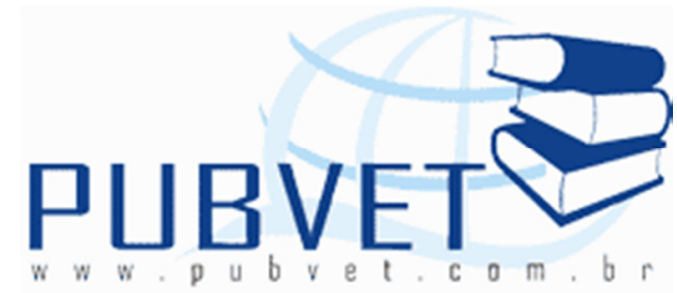

PUBVET, Publicações em Medicina Veterinária e Zootecnia.

\title{
Ultrassom terapêutico e laser de baixa potência no tratamento de abscessos em equinos
}

Júlia de Miranda Moraes ${ }^{1}$, Martha de Oliveira Bravo², Lúcio Neves Huaixan², Paulo César Villa Filho², Fábio Henrique Bezerra Ximenes², Antônio Raphael Teixeira Neto $^{2}$, Eduardo Maurício Mendes de Lima², Roberta Ferro de Godoy ${ }^{3}$

1 Universidade Federal de Goiás - Regional Jataí, Campus Jatobá, BR 364, Km 195, n3800, CEP 75801-615, Jataí-GO. E-mail: mmjulia.edu@gmail.com ${ }^{2}$ Hospital Escola de Grandes Animais, Faculdade de Agronomia e Medicina Veterinária - HVET/UnB, Brasília-DF.

${ }^{3}$ University College of London, Institute of Orthopaedics and Musculoskeletal Science, London, UK.

\section{Resumo}

Lesões cutâneas em equinos possuem uma alta incidência em equinos, devido ao comportamento ativo desses animais. O tratamento correto dessas feridas e sua abordagem terapêutica são imprescindíveis para prevenir complicações como infecções e tecido de granulação exuberante, o que dificultaepitelização e o retorno do animal ao trabalho. O ultrassom terapêutico (UST) e o laser de baixa potência (LBP) são formas não invasivas de tratamento, que estimulam o desenvolvimento de fibroblastos e a produção de colágeno, com o objetivo de 
auxiliar e acelerar a cicatrização da pele desses animais. Desta forma, este estudo teve como objetivo descrever o uso do UST e LBP, como auxiliar na cicatrização de ferida séptica de dois equinos, machos, adultos, atendidos no Hospital Veterinário de Grandes Animais da Universidade de Brasília.

Palavras-chave: cicatrização, equinos, ferida, laser, ultrassom.

\title{
Therapeutic ultrasound and low level laser in treatment of equine abscess
}

\begin{abstract}
Skin lesions in horses have a high incidence, due to the active behavior of these animals. The correct treatment of these wounds and their treatment approach are essential to prevent complications such as infections and exuberant granulation tissue, which hampers epithelialisation of the animal and return to work. Therapeutic ultrasound (TUS) and low-level laser (LLL) is non-invasive forms of treatment, which stimulate the development of fibroblasts and collagen production, aiming to assist and accelerate the healing of the skin of these animals. Thus, this study aimed to describe the use of UST and LBP, as an aid in the healing of septic wound two horses, males, adults, attended the Large Animal Veterinary Hospital of the University of Brasilia.
\end{abstract}

Key-words: laser, healing, horse, ultrasound, wound

\section{Introdução}

O ultrassom terapêutico (UST) e o laser de baixa potência (LBP) são formas não invasivas de tratamento, que estimulam o desenvolvimento de fibroblastos e a produção de colágeno, obtendo uma diminuição no tempo de cicatrização e aumento na força de tensão da ferida (MORAES, 2009; MORAES, 2010). O UST 
MORAES, J.M. et al. Ultrassom terapêutico e laser de baixa potência no tratamento de abscessos em equinos. PUBVET, Londrina, V. 8, N. 16, Ed. 265, Art. 1759, Agosto, 2014.

pode ser definido como uma onda ou pressão sonora propagativa com a capacidade de transferir energia mecânica para os tecidos. O efeito mecânico é causado pelas vibrações sônicas que causam atrito nos complexos celulares, produzindo micro-massagem. O resultado é a excitação celular eaumento da permeabilidade das membranas tissulares, melhorando o metabolismo e a atividade celular (MORAES, 2009; MORAES, 2010; LEVINE, 2008; PRENTICE, 2004).

O LBP é uma radiação eletromagnética, não ionizante, monocromática, coerente e colimada, com ação principalmente nas organelas celulares, em especial nas mitocôndrias, lisossomos e membrana, gerando aumento de ATP e modificando o transporte iônico. Desta forma, o LBP acelera, em curto prazo, a síntese de ATP e em longo prazo, a transcrição e replicação do DNA. Por estimular a angiogênese, o metabolismo e a multiplicação celular, o LBP apresenta potencial para acelerar o reparo tecidual e a multiplicação de vários tipos celulares (MORAES, 2010; LEVINE, 2008; PRENTICE, 2004; ROCHA JÚNIOR, 2006).

O tratamento de feridas nos eqüinos é sempre dificultoso,podendo formar tecido de granulação exuberante o que dificultaa epitelização, requerendo uma avaliação cuidadosa, além de tratamentos diferenciados (MORAES, 2009). Desta forma, este estudo teve como objetivo descrever o uso do UST e LBP, como auxiliar na cicatrização de ferida séptica de eqüinos.

\section{Material e Métodos}

Dois equinos, machos, adultos, da raça Mangalarga Machador, foram atendidos no HVET/UnB com histórico de abscessos na região glútea (Animal A) e cervical (Animal B). Foi realizado o debridamento cirúrgico, com retirada de exsudato purulento e tecido necrótico, resultando em feridas profundas de 
MORAES, J.M. et al. Ultrassom terapêutico e laser de baixa potência no tratamento de abscessos em equinos. PUBVET, Londrina, V. 8, N. 16, Ed. 265, Art. 1759, Agosto, 2014.

$139,2 \mathrm{~cm}^{2}$ e $12,5 \mathrm{~cm}^{2}$ de área, respectivamente (Figuras $1 \mathrm{~A}$ e B).As feridas apresentavam exsudato purulento, hemorragia, bordas eritematosas e edemaciadas e formação moderada de tecido de granulação.

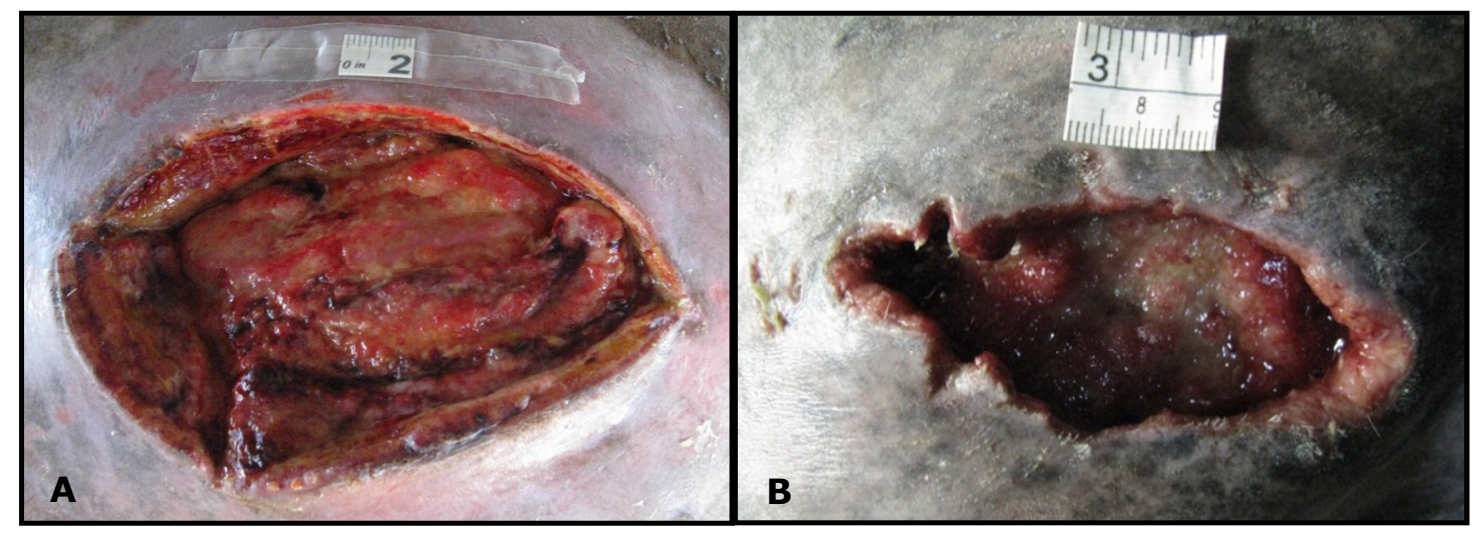

Figura 1A e B: Lesões no início do tratamento.

O tratamento medicamentoso constituiu-se de fenilbutazona $(4,4 \mathrm{mg} / \mathrm{kg}$, IV, SID) por três dias.Realizava-se limpeza duas vezes ao dia com líquido de Dakin, aplicação demetronidazol líquido $(5,0 \mathrm{mg} / \mathrm{mL})$ e açúcar no interior da ferida e utilização repelente ao redor. Concomitantemente,foram instituídos o LBP por aplicação em varredura e nas bordas das feridas, e o UST em modo pulsado, pelo método direto, na presença de gel, sobre a pele tricotomizada ao redor das lesões. No animal A, foram realizadas 28 sessões em 69 dias, sendo inicialmente diariamente, passando para dias alternados na $18^{a}$ sessão.Inicialmente, foram 12 sessões com o UST em freqüência de $1 \mathrm{MHz}$, intensidade de $0,7 \mathrm{~W} / \mathrm{cm}^{2}$ e frequência de pulso de $100 \mathrm{~Hz}$ a $20 \%$ por 14 minutos e LBP com varredura de 60 a $100 \mathrm{~J}$ total na ferida e $7 \mathrm{~J} / \mathrm{cm}^{2}$ nas bordas. Com o preenchimento da ferida pelo tecido de granulação e início da epitelização, suspendeu-se o LBP, e modificou-se o UST para freqüência de $3 \mathrm{MHz}$, intensidade de $0,5 \mathrm{~W} / \mathrm{cm}^{2}$ e frequência de pulso de $100 \mathrm{~Hz}$ a $50 \%$ por 14 minutos, com intuito de melhorar o processo de epitelização. No animal B foram 20 sessões, realizadas diariamente. 
Primeiramente, cinco sessões com o UST em freqüência de $1 \mathrm{MHz}$, intensidade de $0,7 \mathrm{~W} / \mathrm{cm}^{2}$ e frequência de pulso de $100 \mathrm{~Hz}$ a $10 \%$ por 12 minutos e LBP com varredura de $80 \mathrm{~J}$ total na ferida. Igualmente ao animal A, suspendeuse o LBP, e modificou-se o UST para freqüência de $3 \mathrm{MHz}$, intensidade de 0,5W/cm² e frequência de pulso de $100 \mathrm{~Hz}$ a $20 \%$ por 12 minutos, com utilização pomada de mucopolisacaridase misturada ao gel, com intuito de realizarfonoforese para fluidificação da fibrose exuberante existente ao redor da ferida.

Em ambos os animais, conforme ocorria a retração centrípeta das feridas, diminuía-se o tempo de aplicação do UST.Fixava-se uma escala padrão de $2 \mathrm{~cm}$ ao lado das feridas e essas eram fotografadas com câmera digital de alta resolução com intuito de acompanhar a regressão centrípeta dos bordos das feridas. As imagens foram analisadas no programa de imagens Image J, obtendo-se as áreas, em centímetros quadrados, das lesões.

\section{Resultados e Discussão}

$\mathrm{Na}$ primeira semana de tratamento foi observada grande melhora clínica das feridas, apresentando bordas menos eritematosas, diminuição do edema, da exsudação e da profundidade das feridas.Após 15 sessões do animal $A$, a ferida teve uma redução de $76,4 \%$ do tamanho inicial, ficando com 32,8cm², e após 11 sessões do animal B houve redução de $68 \%$ da ferida, ficando com $4 \mathrm{~cm}^{2}$, sendo que nessa etapa ambas se apresentavam superficiais e com epitelização avançada (Figuras 2A e B). 


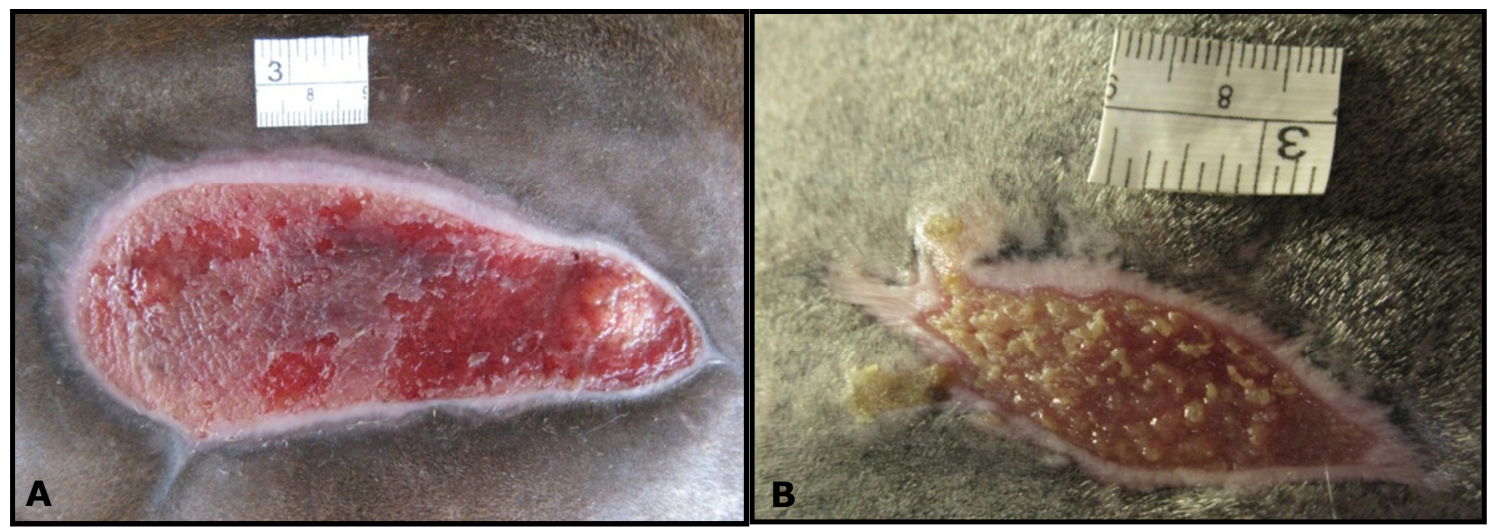

Figura 2A e B: Após 15 e 11 sessões de tratamento, respectivamente.

A utilização da pomada de mucopolisacaridase juntamente com o UST promoveu grande redução da fibrose ao redor da ferida, aprimorando a epitelização e o aspecto cicatricial final.Ao término da terapia as feridas mediam $11,4 \mathrm{~cm}^{2}$ e $2,5 \mathrm{~cm}^{2}$, ou seja, reduziram $91,9 \%$ e $80 \%$ de seus tamanhos iniciais, respectivamente. Foram finalizadas as aplicações de UST mesmo sem a completa retração das feridas, pois essas se encontravam em estágio final de cicatrização, com boa epitelização e retração de bordas e ausência de tecido de granulação exuberante (Figuras $3 \mathrm{~A}$ e B).

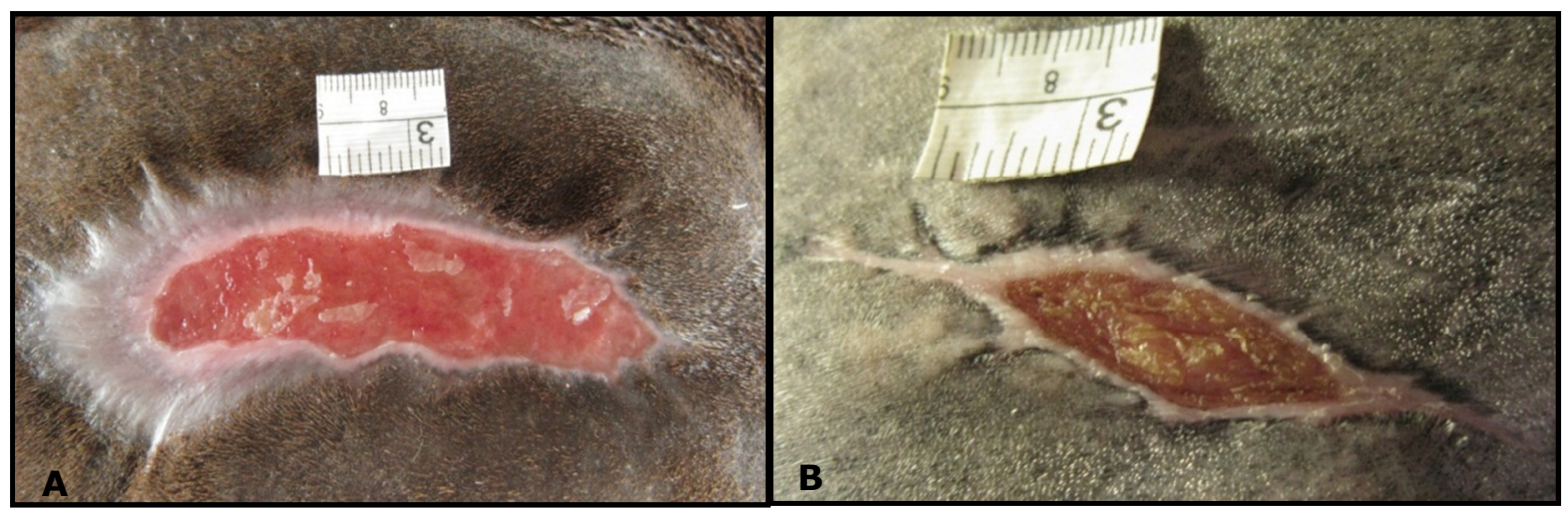

Figura 3A e B: Final do tratamento. 
MORAES, J.M. et al. Ultrassom terapêutico e laser de baixa potência no tratamento de abscessos em equinos. PUBVET, Londrina, V. 8, N. 16, Ed. 265, Art. 1759, Agosto, 2014.

Com o uso do UST e LBP, ocorreu uma rápida modulação da resposta inflamatória, promovendo uma excelente retração das bordas e epitelização tecidual. Segundo autores, estas são características da etapa de resolução da fase inflamatória ou exudativa e início da fase proliferativa, sendo que, o UST e o LBP não exercem efeito antiinflamatório, e sim, aceleram o processo inflamatório e a proliferação celular durante a cicatrização( PRENTICE, 200; LEVINE, 2008).

Isso de deve à uma maior estimulação da proliferação fibroblásticae transformação dos fibroblastos em miofibroblastos, com consequente formação de colágeno, proporcionando contração do tecido de granulação e uma maior força de tensão para a ferida cicatrizada. Dessa forma, a ação angiogênica associada ao incremento da atividade fibroblástica e de macrófagos parece ser o efeito mais consistente dos LBP e UST para o processo de cicatrização (PRENTICE, 2004; ROCHA JÚNIOR, 2006; LEVINE, 2008).

A utilização do UST como artifício de fonoforese, é método altamente eficaz e seguro de transporte transdérmico de drogas (PRENTICE, 2004)como comprovadoneste estudo, observando-se maior desagregação do tecido fibroso, formando um tecido cicatricial mais organizado. As alterações resultantes da ação do LBP e UST nos processos de regeneração tecidual ainda estão em fase incipiente, e, portanto, os mecanismos de ação, bem como a dosagem ótima de terapia, ainda não estão completamente esclarecidos, necessitando de maiores comprovações científicas na área (PRENTICE, 2004; ROCHA JÚNIOR, 2006).

As lesões em eqüinos geralmente são de difícil tratamento, aumentando o tempo de cicatrização fazendo com que estas não evolucionem com perfeita reepitelização (MORAES, 2009; MORAES, 2010) inversamente ao observado neste estudo que, com a utilização prematura do UST e LBP, houve rápida e excelente constituição tecidual. 
MORAES, J.M. et al. Ultrassom terapêutico e laser de baixa potência no tratamento de abscessos em equinos. PUBVET, Londrina, V. 8, N. 16, Ed. 265, Art. 1759, Agosto, 2014.

\section{Conclusão}

As feridas equinas merecem atenção especial no exercício da medicina dessa espécie, em virtude dos seus impactos clínicos e econômicos, bem como à sua alta incidência na medicina equina. Diversos estudos são realizados com o objetivo de otimizar a cicatrização cutânea complicadas. Neste trabalho, com o uso do UST e LBP, ocorreu uma rápida modulação da resposta inflamatória, promovendo uma excelente retração das bordas e epitelização tecidual. Com a utilização do UST como artifício de fonoforese, observou-se maior desagregação do tecido fibroso, formando um tecido cicatricial mais organizado.Os resultados encontrados comprovam a eficácia terapêutica do UST e LBP, para feridas sépticas de eqüinos.

\section{Referências Bibliográficas}

Levine $D$ et al. Reabilitação e fisioterapia na prática de pequenos animais. São Paulo: Roca, 2008, p.95-117.

Moraes JM et al.Ultrassom terapêutico como tratamento na cicatrização de feridas sépticas eqüinas. In: XI Conferência Anual da Abraveq, São Paulo, 2010. Anais..., 29: 261-262.

Moraes JM et al. Therapeuticultrasound as treatment in equinewounds. In: $11^{\text {th }}$ Congress of the world equine veterinary association, Guarujá, 2009. Anais....

Moraes JM et al. Association of as-ga-al low level laser therapy and therapheutic ultrasound in healing of equine septic wounds.In: $11^{\text {th }}$ Congress of the world equine veterinary association, Guarujá, 2009. Anais....,

Prentice W.E. Modalidades terapêuticas para fisioterapeutas. Porto Alegre, 2004: Artmed Editora, 472p.

Rocha Júnior AM et al.Modulação da proliferação fibroblástica e da resposta inflamatória pela terapia a laser de baixa intensidade no processo de reparo tecidual.Anais Brasileiro de Dermatologia, 2006, 81: 150-156. 